\title{
ESTUDO TEÓRICO DE POTENCIAIS AGENTES PARA O TRATAMENTO DA DOENÇA DE ALZHEIMER DERIVADOS DA 8-HIDROXIQUINOLINA COM SUBSTITUINTES DO TIPO $N$-ACIL-HIDRAZONA
}

\author{
Talis U. da Silva ${ }^{\mathrm{a}}$, Leonardo Viana de Freitas ${ }^{\mathrm{b}}$, Nicolás A. Rey e Sérgio de Paula Machado,* \\ aDepartamento de Química Inorgânica, Instituto de Química, Universidade Federal do Rio de Janeiro, 21945-970 Rio de Janeiro \\ - RJ, Brasil \\ 'Instituto Federal de Educação, Ciência e Tecnologia do Rio de Janeiro, 26530-060 Nilópolis - RJ, Brasil \\ c Departamento de Química, Centro Técnico Científico, Pontifícia Universidade Católica do Rio de Janeiro, $22453-900$ Rio de \\ Janeiro - RJ, Brasil
}

Recebido em 06/05/2018; aceito em 08/08/2018; publicado na web em 04/09/2018

\begin{abstract}
THEORETICAL STUDY OF POTENTIAL AGENTS FOR THE TREATMENT OF ALZHEIMER'S DISEASE 8-HIDROXYQUINOLINE DERIVATIVES WITH $N$-ACYLHIDRAZONE TYPE SUBSTITUENTS. In this work, Density Functional Theory was used in the theoretical study of the coordination of three ligands derived from 8-hydroxyquinoline (8-HQ) with N-acylhydrazone: 8-hydroxyquinoline-2-carboxaldehyde isonicotinoyl hydrazone (INHHQ), 2-[(8-hydroxyquinolinyl)methylene] acetohydrazide $\left(8-\mathrm{H}_{2} \mathrm{QH}\right)$ and 2-[(8-hydroxyquinolinyl)methylene] hydrazinecarboxamide $\left(8-\mathrm{H}_{2} \mathrm{QS}\right)$; with the $\mathrm{Zn}^{2+}$ ion. These complexes prevent interactions of the metal ions present in the brain, with the $\beta$-amyloid peptide $(A \beta)$, avoiding the formation of aggregates that are responsible for the development of the Alzheimer's disease. The results show that the three ligands coordinate the $\mathrm{Zn}^{2+}$ ion in a tridentate form through the $\mathrm{O}$ and $\mathrm{N}$ atoms of the 8-hydroxyquinoline center and the $\mathrm{N}$ of the hydrazonic group, completing the coordination sphere with two chloride ions, creating a bipyramidal structure trigonal, different from the structures of the complexes reported in the literature.
\end{abstract}

Keywords: 8-hydroxyquinoline derivatives; Alzheimer's disease; zinc(II) complexes.

\section{INTRODUÇÃO}

\section{Bases moleculares da doença de Alzheimer}

A doença de Alzheimer (DA) é uma disfunção neurodegenerativa, a qual se atribui, atualmente, o papel de causa mais comum de demência em idosos. ${ }^{1}$ Ela provoca danos progressivos no tecido cerebral, ocasionando a perda das sinapses, lesões e morte neuronais, em que a primeira parte comprometida é a região do hipocampo, responsável pelo desenvolvimento da memória, segundo dados da organização mundial da saúde. ${ }^{1,2}$

Ao longo dos anos, algumas hipóteses foram desenvolvidas para tentar elucidar as causas da DA. Numa revisão de De Falco et al. foram listadas seis hipóteses para as causas da DA, entre elas a hipótese da cascata amilóide, entretanto, todas elas acabam apontando para o mesmo denominador comum: a acumulação de placas amilóides no cérebro dos doentes. ${ }^{3}$

A proteína precursora amilóide (APP, no inglês) é uma proteína membranar, a qual é atribuída a função, entre outras, de permitir a plasticidade das sinapses, um processo fundamental, tendo em vista que está diretamente relacionado com a eficiência do processo de construção da memória, do pensamento e do raciocínio. ${ }^{3,4}$ A APP tende a sofrer clivagem pela enzima $\beta$-secretase, cujo produto de reação, um resíduo de 99 átomos de carbono, sofre clivagem pela enzima $\Upsilon$-secretase. A ação desta última provoca a formação de diversos fragmentos de um peptídeo denominado $\beta$-amilóide $(A \beta)$, no qual os dois fragmentos mais comuns são os de $40\left(\mathrm{~A} \beta_{1-40}\right)$ e $42\left(\mathrm{~A} \beta_{1-42}\right)$ resíduos de aminoácidos. ${ }^{1,3}$ Este processo de formação de $\mathrm{A} \beta$ tende a se acentuar com o envelhecimento, quando o petídeo se acumula na região extracelular do cérebro do doente e forma as chamadas placas senis, causando perda neuronal e atrofia cerebral. ${ }^{5}$

\footnotetext{
*e-mail: sergiopm.iq.ufrj.br
}

A hipótese da cascata amilóide, proposta originalmente por Hardy e Higgins em 1992, propõe que o acúmulo de A $\beta$ no cérebro do doente é o fator principal da DA. ${ }^{6}$ Também é atribuído ao acúmulo desse peptídeo alguns efeitos colaterais, como a aglomeração de emaranhados neurofibrilares de proteína tau. ${ }^{7}$ Além disso, em condições normais, essa proteína é responsável por estabilizar os microtúbulos relacionados aos axônios, mas, na presença do $\mathrm{A} \beta$, esses microtúbulos acabam se desintegrando com o acúmulo da proteína, danificando as células nervosas. . $^{1,7,8}$

O peptídeo $\mathrm{A} \beta$ pode adotar uma variedade de formas, dentre as quais as formas monomérica e oligomérica são as que mais servem de base para estudos, sendo atribuído à forma oligomérica o maior grau de toxicidade observado na doença, pois danifica imediatamente as sinapses quando presente no tecido cerebral. ${ }^{4,9} \mathrm{Um}$ estudo recente sugere que os oligômeros de $\mathrm{A} \beta$ (A $\beta \mathrm{O}$ s) prejudicam o funcionamento das sinapses graças a interações com proteínas essenciais para o bom funcionamento dessas. ${ }^{10}$ Assim, uma possível abordagem terapêutica seria inibir o processo de formação de $\mathrm{A} \beta \mathrm{O}$ s a partir da forma monomérica do peptídeo. ${ }^{11}$

Recentemente, um estudo da Universidade Federal do Rio de Janeiro associou a patologia observada na DA à presença de astrocitos defeituosos no tecido cerebral dos doentes. Essas células nervosas sintetizam o fator de crescimento $\beta 1$ (TGF- $\beta 1$ ), essencial para o bom funcionamento das sinapses. Os $A \beta O$ s acumulados no cérebro dos doentes comprometem os astrocitos, o que faz os níveis de TGF- $\beta 1$ diminuírem consideravelmente. Assim, elevar os níveis de TGF- $\beta 1$ no cérebro com DA pode ser uma forma de bloquear a perda da função cognitiva, além desse composto poder atuar como um biomarcador para a DA. ${ }^{12}$

Pelo que já foi discutido, o acúmulo de $\mathrm{A} \beta$ (e sua posterior deposição no cérebro) é tido como a causa central da DA. Mutações em genes que, direta ou indiretamente, contribuem para a maior produção da APP certamente colaboram para iniciar o desenvolvimento da 
doença. Alguns exemplos são o gene da apoliproteína E4 (proteína a qual estudos indicam ser capaz de se ligar à APP, induzindo seu acúmulo no cérebro), os genes que codificam as proteínas presenilina 1 e 2 (que atuam na $\Upsilon$-secretase, responsável direta pela formação do $\mathrm{A} \beta$ ), além do próprio gene que codifica a APP. Este último, inclusive, se encontra nos cromossomos do par 21, sendo que o quadro de trissomia desse par (três cromossomos em vez de dois) produz ainda mais APP do que o normal. É uma explicação para o fato de placas de A $\beta$ serem observadas no cérebro de portadores da síndrome de Down. ${ }^{1,7,13}$

\section{Contribuição do íon $\mathrm{Zn}^{2+}$ na doença de Alzheimer}

Se o acúmulo e posterior deposição de $\mathrm{A} \beta$ no cérebro são fundamentais para a DA, fatores que agravem esse quadro devem ser levados em consideração. Diversos estudos têm apontado para o envolvimento de íons metálicos no processo de agregação do peptídeo no cérebro. Alguns íons, naturalmente presentes no cérebro (especialmente, $\mathrm{Fe}^{3+}, \mathrm{Cu}^{2+} \mathrm{e} \mathrm{Zn}^{2+}$ ), são capazes de se complexar com os monômeros de $\mathrm{A} \beta$, acarretando a oligomerização do peptídeo. ${ }^{14-17}$ Aos íons $\mathrm{Fe}^{3+}$ e $\mathrm{Cu}^{2+}$, por serem redox ativos, também é atribuído o fato de serem responsáveis por produzir espécies reativas de oxigênio no cérebro, causando estresse oxidativo (EROs), agravando os danos cerebrais. ${ }^{16,18,19}$

O zinco é encontrado no cérebro em concentrações em torno de $150 \mu \mathrm{mol} . \mathrm{L}^{-1}$, sendo de vital importância para o bom funcionamento das funções neurológicas. ${ }^{16}$ Ao contrário do ferro e do cobre, o zinco não é redox ativo (devido a sua configuração $\mathrm{d}^{10}$ ), não contribuindo assim para os danos oxidativos observados na DA. Na verdade, alguns estudos atribuem ao zinco um papel de inibidor do processo de formação de EROs, uma vez que atuaria como um antagonista para o cobre e o ferro, competindo com esses dois íons pelos sítios de ligação do $A \beta .^{20,21}$

A região compreendida entre os 16 primeiros resíduos de aminoácidos do $\mathrm{A} \beta$ parece ser de fato a região onde se encontra o sítio de coordenação do zinco ao peptídeo. $\mathrm{O}$ pH parece influenciar no processo de coordenação, em que diferentes estruturas para o complexo [ZnA $\beta$ ] são propostas. Entretanto, há um consenso de que os resíduos Asp1, His6, Glu11, His13, His14 estão envolvidos na coordenação desse metal. ${ }^{14,15,22,23}$ Esses resíduos também teriam participação direta no processo de formação de $\mathrm{A} \beta \mathrm{O}$ s. ${ }^{24}$

O zinco participa ativamente do processo de formação da memória, com a sua concentração nas sinapses sendo modulada pelo seu transportador, ZnT3. Os níveis deste íon tendem a decair com o avanço da idade, sendo tal efeito mais pronunciado em portadores da $\mathrm{DA}$, em razão da complexação desse metal com o $\mathrm{A} \beta .^{25,26}$

Quando na presença de mais de um íon metálico, pode ocorrer a formação de complexos hetero-bimetálicos de $\mathrm{A} \beta$ com $\mathrm{Cu}^{2+}, \mathrm{Cu}^{+}$ e $\mathrm{Zn}^{2+}$, dependendo da concentração destes íons. Isso pode implicar diretamente na eficácia de tratamentos que envolvam a remoção desses íons dos sítios de ligação do peptídeo. ${ }^{5}$

\section{Metodologias de tratamento}

A busca por um tratamento eficiente para combater a DA vem estimulando uma grande quantidade de estudos, que visam combater a doença em diversas frentes. No intuito de combater a formação de emaranhados fibrilares de proteína tau (causado pela hiperfosforilação dessa na presença do $A \beta$ ) e o consequente acúmulo deles no cérebro, foi sugerido o uso de selenato de sódio como agente inibitório da hiperfosforilação da proteína tau in vitro e in vivo (testes em animais transgênicos). ${ }^{27}$

Como a participação de íons metálicos dentro do contexto da doença já é conhecida, vem-se propondo terapias baseadas na quelação desses íons e, mais recentemente, no uso dos denominados compostos atenuadores da interação metal-proteína (MPACs, em inglês), capazes de bloquear as interações metal-proteína anômalas, com o intuito de redisponibilizar os íons metálicos para o organismo, após bloquear a interação metal-peptídeo, a fim de que esses cumpram suas funções biológicas normalmente ao invés de serem eliminados do organismo como ocorre na quelação., $3,28,29$

A 8-hidroxiquinolina (8-HQ) (Figura 1a), também conhecido como 8-quinolinol, vem sendo amplamente utilizada como ponto de partida para a síntese de compostos com potencial atividade de combater a DA por meio da complexação com os íons metálicos envolvidos na doença (como o cobre e o zinco). ${ }^{11,28,29}$ Características como lipofilicidade (o que possibilita atravessar a barreira hematoencefálica), baixa massa molecular e afinidade por metais divalentes tornam a 8-HQ uma boa opção de composto base para a síntese de agentes ativos contra a DA..$^{30,31}$ A 8-HQ possui dois átomos coordenantes: o $\mathrm{N}$ do anel quinolínico e o $\mathrm{O}$ fenólico, que atuam como um ligante bidentado e formando complexos e estequiometria ML2 com o zinco/cobre. Foi verificado também que seus derivados são capazes, em algum grau, de inibir a formação de $A \beta O$ s. $^{11,28}$

O clioquinol (CQ) (Figura 1e), um derivado halogenado da 8-HQ, é tido como o primeiro derivado da 8-HQ a ser testado como potencial fármaco para combater a DA, por ter-se demonstrado capaz de atravessar a barreira hematoencefálica e também de complexar o cobre e o zinco. ${ }^{1,21}$ Estudos teóricos desse ligante também foram feitos, a fim de ajudar a elucidar a esfera de coordenação do zinco na presença do CQ. ${ }^{32,33}$ Compostos baseados no CQ, como o M30 (Figura 1c) e o PBT2 (Figura 1d), também foram propostos como potenciais fármacos contra a DA. . $^{3435}$

Gomes et al. sintetizaram e caracterizaram três compostos baseados na 8-HQ, entre eles, a semicarbazona 2-[(8-hidroxiquinolinil)metileno] hidrazina carboxamida $\left(8-\mathrm{H}_{2} \mathrm{QS}\right)$ (Figura $\left.1 \mathrm{~h}\right)$ e a acetohidrazona 2-[(8-hidroxiquinolinil)metileno] acetohidrazida $\left(8-\mathrm{H}_{2} \mathrm{QH}\right)$ (Figura $1 \mathrm{~g}$ ), e testaram a capacidade desses de complexar o íon cobre(II) na presença de $\mathrm{A} \beta$, obtendo bons resultados. Os dois compostos mencionados apresentaram boa capacidade antioxidante e inibidora da agregação da $\mathrm{A} \beta .{ }^{36}$ Já Wang et al. propuseram uma série de derivados da 8-HQ contendo selênio, em que o composto intitulado 8a (Figura 1b) foi o que demonstrou maior eficácia para um potencial fármaco. As análises feitas com esse composto mostraram que ele é um bom agente complexante para $\mathrm{Cu}, \mathrm{Fe}$ e $\mathrm{Zn}$, além de retardar a agregação do $\mathrm{A} \beta$ na presença desses íons. ${ }^{37}$ Além disso, outras classes de ligantes derivados da 8-HQ, como compostos do tipo bis-8-HQ (dois grupos 8-HQ unidos de forma covalente por um grupo que funciona como ponte) (Figura 1i) e equivalentes tióis da 8-HQ (com um átomo de $\mathrm{S}$ no lugar do $\mathrm{O}$ fenólico) também foram sintetizados. ${ }^{17,29}$

Freitas et al. propuseram o ligante 8-hidroxiquinolina-2-carboxialdeído isonicotinoíl hidrazona (INHHQ) (Figura 1f) como um potencial MPAC para o combate da DA, em que esse demonstrou ser capaz de complexar o zinco e o cobre na presença do $A \beta$, além de atravessar a barreira hematoencefálica e apresentar baixa toxicidade quando testado em ratos. ${ }^{1,28,38} \mathrm{~A}$ estrutura proposta por Freitas (Figura 2) para o complexo [ $\mathrm{Zn}(\mathrm{INHHQ}) \mathrm{Cl}_{2}$ ] possui uma geometria de coordenação bipiramidal trigonal, com o INHHQ agindo como ligante tridentado, coordenando-se pelo $\mathrm{N}$ quinolínico, o O carbonílico e o $\mathrm{N}$ do grupo hidrazônico. ${ }^{1}$

Os compostos $8-\mathrm{H}_{2} \mathrm{QH}$ e $8-\mathrm{H}_{2} \mathrm{QS}$ possuem estruturas bem semelhantes à do INHHQ, em que a única diferença se dá no grupo $\mathrm{R}$ terminal (Figura 3), logo, os três ligantes devem formar complexos de perfis semelhantes com o íon zinco. Assim, no presente trabalho, sugerimos uma nova forma de coordenação para o complexo entre esses ligantes e o íon zinco através do estudo teórico dos ligantes e dos respectivos possíveis complexos formados. 
<smiles>C#CC[Se]c1ccc(O)c2ncccc12</smiles>

b<smiles>Oc1cccc2cccnc12</smiles>

a<smiles>O=C(N/N=C/c1ccc2cccc(O)c2n1)c1ccncc1</smiles>

f<smiles>C#CCN(C)Cc1ccc(O)c2ncccc12</smiles>

C<smiles>CCc1ccc2cccc(O)c2n1</smiles><smiles>CC(=O)NN=O</smiles>

g<smiles>Cc1cc(C)c2ccc(CN(C)C)nc2c1O</smiles>

d<smiles>Oc1c(I)cc(Cl)c2cccnc12</smiles>

e<smiles>CCc1ccc2cccc(O)c2n1</smiles><smiles>NNC(N)=O</smiles><smiles>Oc1cccc2ccc(Cc3ccc4cccc(O)c4n3)nc12</smiles>

h

Figura 1. Estruturas da 8-HQ (a) e de alguns de seus derivados propostos como potenciais fármacos para o combate da DA: $8 a(b), M 30$ (c), $P B T 2(d)$, CQ (e), INHHQ (f), 8- $\mathrm{H}_{2} \mathrm{QH}(\mathrm{g}), 8-\mathrm{H}_{2} \mathrm{QS}(\mathrm{h})$ e 2,2 - (2,2-propanodil)-bis-8-HQ (i)

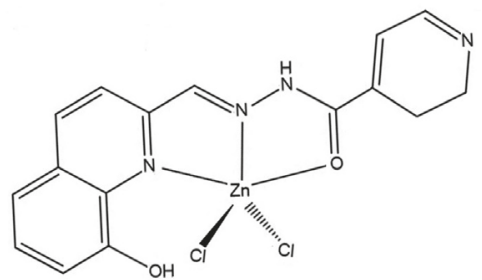

Figura 2. Proposta estrutural do complexo [ $\left.\mathrm{Zn}(\mathrm{INHHQ}) \mathrm{Cl}_{2}\right]$<smiles>CC(=O)N/N=C/c1ccc2cccc(O)c2n1</smiles>

Figura 3. Estrutura genérica de ligantes derivados da 8-HQ com substituintes $\mathrm{N}$-acil-hidrazona. Os átomos de $\mathrm{C}, \mathrm{N}$ e $\mathrm{O}$ foram numerados para auxiliar nas análises dos parâmetros geométricos e eletrônicos

\section{METODOLOGIA}

Os cálculos foram realizados no programa Gaussian 09. ${ }^{39}$ As estruturas otimizadas dos ligantes e complexos foram obtidas através da teoria do funcional de densidade $(D F T)$ com o funcional de troca e correlação híbrido B3LYP (Becke, três parâmetros, Lee-Yang-Parr), que é um dos funcionais mais utilizados no campo dos metais de transição. ${ }^{19,22,32,40,41} \mathrm{O}$ conjunto de bases escolhido a ser associado a este funcional foi o LanL2DZ. As ausências de frequências imaginárias nas estruturas otimizadas confirmam que estas se encontraram num mínimo de energia.
Foram obtidos os percentuais de participação dos centros de coordenação de cada ligante no orbital molecular de fronteira HOMO (Highest Occupied Molecular Orbital), orbital responsável por doar densidade eletrônica para o $\mathrm{Zn}^{2+}$, a fim de verificar quais átomos da estrutura teriam a maior propensão a se coordenar ao metal. Também foram obtidos os diagramas de contorno deste orbital para cada um dos ligantes.

Foram propostas quatro estruturas para cada um dos complexos [Zn(INHHQ) $\left.\mathrm{Cl}_{2}\right],\left[\mathrm{Zn}\left(8-\mathrm{H}_{2} \mathrm{QH}\right) \mathrm{Cl}_{2}\right]$ e $\left[\mathrm{Zn}\left(8-\mathrm{H}_{2} \mathrm{QS}\right) \mathrm{Cl}_{2}\right]$, sendo que essas estruturas são representadas de forma genérica na Figura 4 , com o grupo R diferenciando cada um dos três complexos. Para as geometrias de partida utilizadas, o zinco se encontra em um ambiente<smiles></smiles><smiles></smiles><smiles>[R]C(=O)NN1C=C2C=Cc3cccc(O)c3N2[C@](C)(Cl)C1(Cl)Cl</smiles><smiles></smiles>

4

Figura 4. Estrutura genérica dos quatro isômeros propostos para o complexo formado entre um ligante derivado da 8-HQ com substtuinte N-acil-hidrazona e dois cloros 
Tabela 1. Parâmetros estruturais selecionados dos ligantes INHHQ, 8- $\mathrm{H}_{2} \mathrm{QH}$ e 8- $\mathrm{H}_{2} \mathrm{QS}$

\begin{tabular}{|c|c|c|c|c|c|}
\hline Distância de ligação $(\AA ̊)$ & INHHQ experimental $^{28}$ & INHHQ teórico & $8-\mathrm{H}_{2} \mathrm{QH}$ experimental ${ }^{36}$ & 8- $\mathrm{H}_{2} \mathrm{QH}$ teórico & 8- $\mathrm{H}_{2} \mathrm{QS}$ teórico \\
\hline $\mathrm{C}_{1}=\mathrm{O}_{2}$ & $1,227(18)$ & 1,257 & $1,230(2)$ & 1,251 & 1,251 \\
\hline $\mathrm{N}_{1}-\mathrm{C}_{1}$ & $1,345(2)$ & 1,390 & $1,358(2)$ & 1,401 & 1,415 \\
\hline $\mathrm{N}_{1}-\mathrm{N}_{2}$ & $1,386(18)$ & 1,391 & $1,363(2)$ & 1,419 & 1,420 \\
\hline $\mathrm{C}_{3}=\mathrm{N}_{3}$ & $1,319(2)$ & 1,343 & $1,328(2)$ & 1,344 & 1,343 \\
\hline $\mathrm{C}_{2}=\mathrm{N}_{2}$ & $1,270(2)$ & 1,310 & $1,280(2)$ & 1,307 & 1,307 \\
\hline $\mathrm{O}_{1}-\mathrm{C}_{8}$ & $1,358(2)$ & 1,389 & $1,358(2)$ & 1,389 & 1,389 \\
\hline \multicolumn{6}{|l|}{ Ângulo de ligação $\left(^{\circ}\right)$} \\
\hline $\mathrm{C}_{1}-\mathrm{N}_{1}-\mathrm{N}_{2}$ & $118,4(13)$ & 130,28 & $120,3(1)$ & 125,6 & 123,8 \\
\hline $\mathrm{C}_{3}-\mathrm{N}_{3}-\mathrm{C}_{7}$ & $117,8(13)$ & 118,87 & $116,5(1)$ & 119,3 & 119,4 \\
\hline $\mathrm{C}_{2}-\mathrm{N}_{2}-\mathrm{N}_{1}$ & $115,5(13)$ & 121,88 & $116,5(1)$ & 121,7 & 121,4 \\
\hline $\mathrm{N}_{1}-\mathrm{C}_{1}-\mathrm{R}$ & $115,0(13)$ & 115,22 & $122,9(1)$ & 114,1 & 113,1 \\
\hline $\mathrm{O}_{1}-\mathrm{C}_{8}-\mathrm{C}_{7}$ & $118,6(15)$ & 117,04 & $118,0(1)$ & 117,0 & 117,0 \\
\hline
\end{tabular}

de coordenação bipiramidal trigonal nos isômeros 1 e 2, enquanto que nos isômeros 3 e 4 o ambiente de coordenação ao redor do zinco é tetraédrico.

\section{RESULTADOS E DISCUSSÃO}

Os principais parâmetros estruturais dos ligantes INHHQ, 8- $\mathrm{H}_{2} \mathrm{QH}$ e $\mathrm{H}_{2} \mathrm{QS}$ são apresentados a seguir (Tabela 1), bem como suas estruturas otimizadas (Figura 5). Os resultados teóricos obtidos para os ligantes foram comparados com os resultados experimentais obtidos para o INHHQ ${ }^{28}$ e o $8-\mathrm{H}_{2} \mathrm{QH},{ }^{36}$ a fim de validar nossas estruturas teóricas. Não foram encontrados os valores experimentais referentes ao $8-\mathrm{H}_{2} \mathrm{QS}$, mas esse apresentou valores teóricos similares aos dos outros dois. Algo que deve ser ressaltado é que, embora tanto Freitas et al. quanto Gomes et al. tenham realizado o estudo teórico de seus respectivos ligantes, o enfoque deles se deu apenas nas análises vibracionais e geométricas, não sendo feita nenhuma análise dos orbitais de fronteira, o que é feito neste trabalho, visando compreender melhor a reatividade dos ligantes frente ao íon zinco.

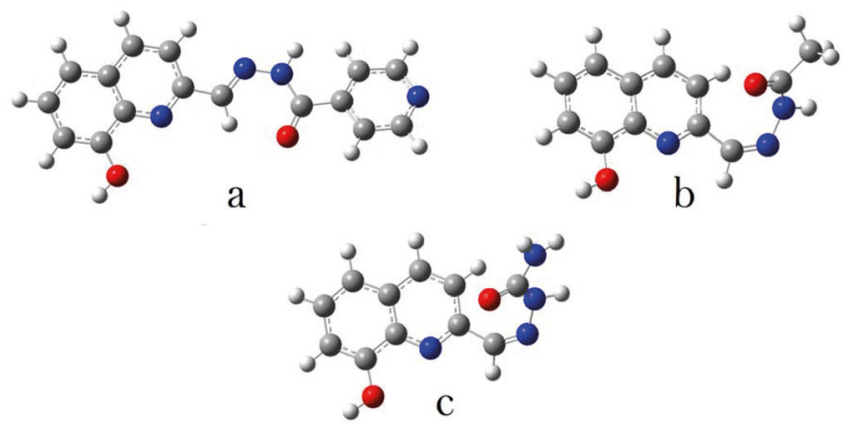

Figura 5. Estruturas otimizadas dos ligantes $I N H H Q(a), 8-H_{2} Q H(b) e$ $8-H_{2} Q S(c)$

Observou-se que os valores teóricos encontrados concordam com os encontrados experimentalmente por Freitas et al. e Gomes et al.

Os cálculos realizados nesse trabalho também forneceram as frequências vibracionais (Tabela 2) e o espectro teórico de infravermelho (IV) do ligante INHHQ (Figura 1S), que apresentaram boa concordância com os resultados experimentais obtidos por Freitas et al. ${ }^{28}$

Os diagramas de contorno do orbital de fronteira HOMO para os três ligantes são apresentados na Figura 6, enquanto que os percentuais de participação dos possíveis átomos coordenantes, presentes na estrutura dos três ligantes, são apresentados na Tabela 3. Já os
Tabela 2. Principais vibrações do ligante INHHQ $\left(\mathrm{cm}^{-1}\right)$. Os valores se encontram fora de escala

\begin{tabular}{lcc}
\hline & Experimental $^{28}$ & Teórico \\
\hline Estiramento $\mathrm{O}_{1}-\mathrm{H}$ & 3396 & 3692 \\
Estiramento $\mathrm{N}_{1}-\mathrm{H}$ & 3183 & 3665 \\
Estiramento $\mathrm{C}_{1}-\mathrm{O}_{2}$ & 1656 & 1667 \\
Estiramento $\mathrm{C}_{2}=\mathrm{N}_{2}$ & 1647 & 1619 \\
Estiramento $\mathrm{C}_{3}=\mathrm{N}_{3}$ & 1556 & 1594 \\
Estiramento $\mathrm{C}_{8}-\mathrm{OH}$ & 1232 & $1287-1304$ \\
\hline
\end{tabular}
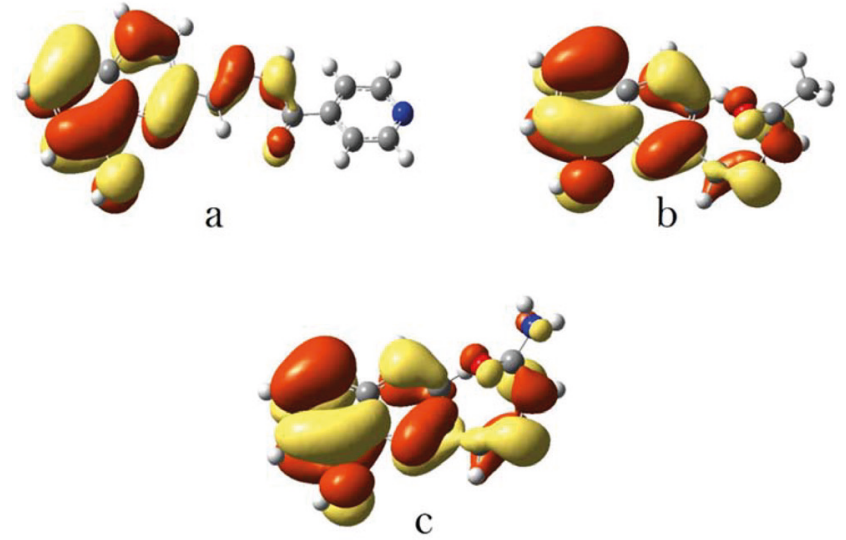

Figura 6. Diagramas de contorno do orbital HOMO obtidos para os ligantes INHHQ (a), 8- $\mathrm{H}_{2} \mathrm{QH}(b)$ e 8- $\mathrm{H}_{2} \mathrm{QS}(c)$

Tabela 3. Percentuais de participação no HOMO dos principais átomos coordenantes dos ligantes

\begin{tabular}{cccccc}
\hline & \multicolumn{5}{c}{$\operatorname{HOMO}(\%)$} \\
\cline { 2 - 6 } & $\mathrm{N}_{3}$ & $\mathrm{O}_{1}$ & $\mathrm{~N}_{2}$ & $\mathrm{~N}_{1}$ & $\mathrm{O}_{2}$ \\
\hline INHHQ & 7,009 & 11,15 & 5,489 & 5,213 & 3,118 \\
8- $\mathrm{H}_{2} \mathrm{QH}$ & 6,789 & 10,09 & 8,365 & 7,109 & 4,243 \\
$8-\mathrm{H}_{2} \mathrm{QS}$ & 6,785 & 9,439 & 9,363 & 8,345 & 3,292 \\
\hline
\end{tabular}

dados referentes ao orbital LUMO do ligantes foram desconsiderados, uma vez que os ligantes atuarão como bases de Lewis, doando pares de elétrons. O diagrama de contorno do HOMO mostra que 
esse orbital possui caráter predominantemente ligante, no qual as maiores contribuições provêm do centro quinolínico (átomos $\mathrm{N}_{3} \mathrm{e}$ $\mathrm{O}_{1}$ ), e dos átomos $\mathrm{N}_{1}, \mathrm{~N}_{2}$ e $\mathrm{O}_{2}$.

Como se pode observar pela Tabela 3 , a participação no HOMO dos quatro possíveis átomos coordenantes do INHHQ segue a seguinte ordem decrescente: $\mathrm{O}$ fenólico $\left(\mathrm{O}_{1}\right)>\mathrm{N}$ quinolínico $\left(\mathrm{N}_{3}\right)>\mathrm{N}$ da azometina $\left(\mathrm{N}_{2}\right)>\mathrm{N}_{1}>\mathrm{O}$ carbonílico $\left(\mathrm{O}_{2}\right)$. Já para o $8-\mathrm{H}_{2} \mathrm{QH}$ e para o 8- $\mathrm{H}_{2} \mathrm{QS}$, essa ordem se altera para $\mathrm{O}$ fenólico $\left(\mathrm{O}_{1}\right)>\mathrm{N}$ da azometina $\left(\mathrm{N}_{2}\right)>\mathrm{N}_{1}>\mathrm{N}$ quinolínico $\left(\mathrm{N}_{3}\right)>\mathrm{O}$ carbonílico $\left(\mathrm{O}_{2}\right)$. Embora a participação de $\mathrm{N}_{1}$ no HOMO em $8-\mathrm{H}_{2} \mathrm{QH}$ e $8-\mathrm{H}_{2} \mathrm{QS}$ seja superior a de $\mathrm{N}_{3}$, uma coordenação por $\mathrm{N}_{1}$ seria inviável, já que formaria um anel de três membros junto com $\mathrm{N}_{2}$ e o zinco, enquanto que a coordenação por $\mathrm{N}_{3}$ formaria um anel de cinco membros com $\mathrm{N}_{2}$ e o zinco. Assim, os presentes dados indicam que, para que um ligante do tipo 8-HQ-(substituinte $\mathrm{N}$-acil-hidrazona) possa agir como ligante tridentado, os átomos coordenantes serão, preferencialmente, $\mathrm{O}_{1}, \mathrm{~N}_{3} \mathrm{e}$ $\mathrm{N}_{2}$. Esses resultados estão, a princípio, em desacordo com a estrutura proposta por Freitas ${ }^{1}$ para o complexo [ $\left.\mathrm{Zn}(\mathrm{INHHQ}) \mathrm{Cl}_{2}\right]$ (mostrado anteriormente na Figura 2).

A partir dos ligantes, foram obtidas as estruturas otimizadas dos quatro isômeros propostos neste trabalho para cada um dos complexos $\left[\mathrm{Zn}(\mathrm{INHHQ}) \mathrm{Cl}_{2}\right],\left[\mathrm{Zn}\left(8-\mathrm{H}_{2} \mathrm{QH}\right) \mathrm{Cl}_{2}\right]$ e $\left[\mathrm{Zn}\left(8-\mathrm{H}_{2} \mathrm{QS}\right) \mathrm{Cl}_{2}\right]$. A Figura 7 traz as estruturas dos quatro isômeros do complexo [ $\mathrm{Zn}$ (INHHQ) $\mathrm{Cl}_{2}$ ], enquanto as estruturas otimizadas dos quatros isômeros dos dois complexos restantes são apresentandas nas Figuras 2S e 3S.
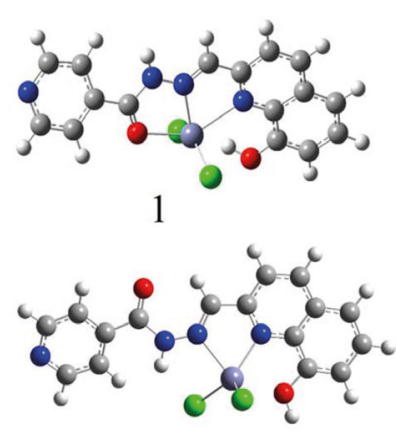

3
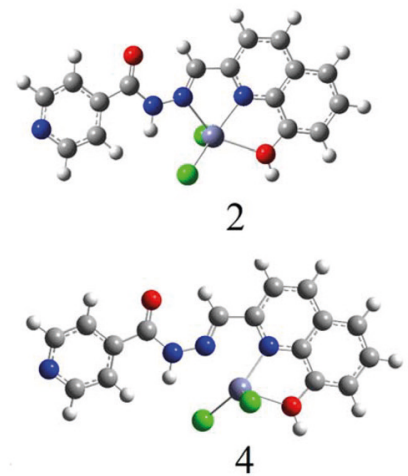

Figura 7. Estruturas otimizadas dos quatro isômeros propostos para o complexo $\left[\mathrm{Zn}(\mathrm{INHHQ}) \mathrm{Cl}_{2}\right]$

Das quatro estruturas propostas para os complexos estudados, o isômero 1 simula a estrutura proposta por Freitas ${ }^{1}$ para o complexo [Zn(INHHQ)Cl $\mathrm{I}_{2}$, na qual o ligante se coordena pelos átomos $\mathrm{N}_{3}, \mathrm{~N}_{2}$ e $\mathrm{O}_{2}$ (O carbonílico), formando um complexo de geometria bipiramidal trigonal ao redor do zinco, com dois átomos de cloro oriundos do sal $\mathrm{ZnCl}_{2}$, utilizado para sintetizar o complexo. Os átomos $\mathrm{N}_{3} \mathrm{e}$ $\mathrm{O}_{2}$ se encontram na posição axial, enquanto $\mathrm{N}_{2}$ e os dois cloros se encontram na posição equatorial. $\mathrm{O}$ isômero 2 é a estrutura proposta por nós, em que os átomos coordenantes são $\mathrm{O}_{1}$ (O fenólico), $\mathrm{N}_{3} \mathrm{e}$ $\mathrm{N}_{2}$ (os átomos do ligante com maior percentual de participação no HOMO), além dos dois átomos de cloro, formando uma estrutura de geometria também bipiramidal trigonal ao redor do zinco. O átomo $\mathrm{O}_{1}$ foi mantido protonado devido ao fato de os dados experimentais de Freitas ${ }^{1}$ indicarem que esse átomo permanece protonado após a coordenação. Além dessas estruturas, outras duas foram propostas por nós: o isômero 3, com o ligante se coordenando pelos átomos $\mathrm{N}_{2}$ e $\mathrm{N}_{3}$, e o isômero 4, em que o ligante se coordena apenas pelo centro quinolínico $\left(\mathrm{N}_{3}\right.$ e $\left.\mathrm{O}_{1}\right)$, com ambos apresentando uma geometria tetraédrica ao redor do zinco. Em todos os isômeros, o ligante se coordena em sua forma neutra, sendo as duas cargas positivas do zinco neutralizadas pelas cargas dos cloretos. Além disso, foram analisados os dados de energia dos isômeros de cada complexo obtido, a fim de verificar qual a estrutura mais estável para cada complexo.

Os cálculos revelaram que os isômeros 2, 3 e 4 de cada complexo convergiram para a mesma estrutura (pois apresentaram valores de energia e distâncias de ligação rigorosamente idênticos), em que aquele que melhor representa a estrutura de cada complexo é o seu respectivo isômero 2, com um ambiente bipiramidal trigonal distorcido ao redor do zinco. Portanto, a partir de agora, o estudo se resumirá em comparar os dados referentes aos isômeros 1 e 2 de cada complexo. A Tabela 4 apresenta os valores de energia dos isômeros 1 e 2 para os três complexos.

Tabela 4. Energias relativas (Kcal/mol) para os isômeros 1 e 2 dos complexos [Zn(INHHQ)Cl $\left.{ }_{2}\right],\left[\mathrm{Zn}\left(8-\mathrm{H}_{2} \mathrm{QH}\right) \mathrm{Cl}_{2}\right]$ e $\left[\mathrm{Zn}\left(8-\mathrm{H}_{2} \mathrm{QS}\right) \mathrm{Cl}_{2}\right]$

\begin{tabular}{ccc}
\hline Complexo & 1 & 2 \\
\hline$\left[\mathrm{Zn}(\mathrm{INHHQ}) \mathrm{Cl}_{2}\right]$ & 7,722 & 0,0 \\
{$\left[\mathrm{Zn}\left(8-\mathrm{H}_{2} \mathrm{QH}\right) \mathrm{Cl}_{2}\right]$} & 6,499 & 0,0 \\
{$\left[\mathrm{Zn}\left(8-\mathrm{H}_{2} \mathrm{QS}\right) \mathrm{Cl}_{2}\right]$} & 13,35 & 0,0 \\
\hline
\end{tabular}

Como é mostrado na Tabela 4, para os três complexos, o isômero 2 representou o mínimo de energia frente ao isômero 1 (que possui energia consieravelmente mais alta), indicando que, para os complexos propostos, a estrutura do isômero 1 parece ser a menos razoável.

A Tabela 5 apresenta as principais distâncias de ligação para os dois isômeros do complexo [ $\left.\mathrm{Zn}(\mathrm{INHHQ}) \mathrm{Cl}_{2}\right]$.

Tabela 5. Principais distâncias de ligação para os isômeros 1 e 2 do complexo [Zn(INHHQ) $\left.\mathrm{Cl}_{2}\right]$

\begin{tabular}{ccc}
\hline Distância de ligação $(\AA)$ & 1 & 2 \\
\hline $\mathrm{C}_{1}=\mathrm{O}_{2}$ & 1,258 & 1,259 \\
$\mathrm{O}_{1}-\mathrm{H}$ & 1,000 & 0,9774 \\
$\mathrm{C}_{2}=\mathrm{N}_{2}$ & 1,298 & 1,307 \\
$\mathrm{C}_{3}=\mathrm{N}_{3}$ & 1,352 & 1,345 \\
$\mathrm{O}_{1}-\mathrm{C}_{8}$ & 1,364 & 1,398 \\
$\mathrm{O}_{1}-\mathrm{Zn}$ & 3,321 & 2,337 \\
$\mathrm{O}_{2}-\mathrm{Zn}$ & 2,289 & 5,123 \\
$\mathrm{~N}_{2}-\mathrm{Zn}$ & 2,169 & 2,274 \\
$\mathrm{~N}_{3}-\mathrm{Zn}$ & 2,433 & 2,132 \\
\hline
\end{tabular}

Comparando-se os isômeros 1 e 2 do [ $\mathrm{Zn}(\mathrm{INHHQ}) \mathrm{Cl}_{2}$ ], a distância $\mathrm{C}_{1}=\mathrm{O}_{2}$ é bem similar, sendo até maior no isômero $2(1,258$ $\AA$ em 1 e 1,259 $\AA$ em 2), quando se esperaria que essa distância fosse maior no isômero 1 , já que a ligação $\mathrm{C}=\mathrm{O}$ estaria enfraquecida frente a coordenação de $\mathrm{O}_{2}$ ao zinco graças à densidade eletrônica da ligação $\mathrm{C}=\mathrm{O}$ ser direcionada ao centro metálico. No ligante, essa distância foi calculada como $1,257 \AA$, bem próxima às encontradas nos complexos, indicando que a coordenação de $\mathrm{O}_{2}$ ao zinco não é efetiva. A distância $C_{3}=N_{3}(1,343 \AA$ no ligante) aumentou no isômero $1(1,352 \AA)$, enquanto que no isômero 2 o aumento foi pouco pronunciável $\left(1,345 \AA\right.$ ). A distância $\mathrm{C}_{2}=\mathrm{N}_{2}(1,310 \AA$ no ligante) diminuiu de forma pouco significativa em ambos os isômeros $(1,298 \AA$ em $1 \mathrm{e}$ $1,307 \AA ̊$ em 2), indicando uma fraca coordenação de $\mathrm{N}_{2}$ ao zinco, algo já esperado graças ao baixo valor de participação de $\mathrm{N}_{2}$ no HOMO do ligante. A distância $\mathrm{C}_{8}-\mathrm{O}_{1}$, que no ligante foi calculada em 1,389 $\AA$, foi encontrada no complexo em 1,364 ̊ no isômero 1, e 1,398 no isômero 2 , no qual esta última aponta para a coordenação de $\mathrm{O}_{1}$ ao zinco no isômero 2, com a ligação $\mathrm{C}_{8}-\mathrm{O}_{1}$ se encontrando mais 
enfraquecida graças à densidade eletrônica da ligação $\mathrm{C}_{8}-\mathrm{O}_{1}$ ser direcionada ao íon zinco após a coordenação. Esses resultados indicam que a coordenação ao zinco foi mais efetiva para $\mathrm{O}_{1}$ do que para $\mathrm{O}_{2}$.

Ao se observar as distâncias de $\mathrm{O}_{1}, \mathrm{O}_{2}, \mathrm{~N}_{2}$ e $\mathrm{N}_{3}$ ao zinco, percebese que a distância $\mathrm{N}_{3}-\mathrm{Zn}$ apresentou um valor $(2,433 \AA$ ) no isômero 1 condizente com uma ligação relativamente fraca. Além disso, dos oxigênios que não se encontram coordenados em cada isômero, $\mathrm{O}_{1}$ se encontra a uma distância inferior do zinco $(3,321 \AA)$ no isômero 1 do que $\mathrm{O}_{2}$ no isômero $2(5,123 \AA)$, indicando uma possível preferência do metal de se coordenar a $\mathrm{O}_{1}$ no referido complexo.

A análise dos valores de distância de ligação dos isômeros dos complexos $\left[\mathrm{Zn}\left(8-\mathrm{H}_{2} \mathrm{QH}\right) \mathrm{Cl}_{2}\right]$ e $\left[\mathrm{Zn}\left(8-\mathrm{H}_{2} \mathrm{QS}\right) \mathrm{Cl}_{2}\right]$ (Tabelas $1 \mathrm{~S}$ e $2 \mathrm{~S}$, respectivamente), revelaram que a distância $\mathrm{C}_{1}=\mathrm{O}_{2}$ aumentou de 1,251 $\AA$ nos ligantes para 1,255 ̊ (isômero 1) e 1,256 ̊ (isômero 2) no complexo $\left[\mathrm{Zn}\left(8-\mathrm{H}_{2} \mathrm{QH}\right) \mathrm{Cl}_{2}\right]$, e 1,259 $\AA$ (isômero 1) e 1,257 ̊ (isômero 2) no complexo $\left[\mathrm{Zn}\left(8-\mathrm{H}_{2} \mathrm{QS}\right) \mathrm{Cl}_{2}\right]$, indicando um aumento da ligação $\mathrm{C}=\mathrm{O}$ mesmo no isômero em que este átomo não se encontra coordenado. A ligação $\mathrm{C}_{8}-\mathrm{O}_{1}$ aumentou de $1.389 \AA$ ก nos ligantes para 1,363 Å (isômero 1) e 1,397 ̊̊ (isômero 2) no complexo [ $\left.\mathrm{Zn}\left(8-\mathrm{H}_{2} \mathrm{QH}\right) \mathrm{Cl}_{2}\right]$, e para 1,377 ̊ (isômero 1) e 1,398 ̊ (isômero 2) no complexo [ $\mathrm{Zn}(8$ $\left.\mathrm{H}_{2} \mathrm{QS}\right) \mathrm{Cl}_{2}$ ]. Esses dados indicam que o átomo de $\mathrm{O}$ com coordenação mais efetiva nesses complexos foi $\mathrm{O}_{1}$, já que a distância $\mathrm{C}_{8}-\mathrm{O}_{1}$ foi superior no isômero 2 quando comparado ao isômero 1 , enquanto que a distância $\mathrm{C}_{1}=\mathrm{O}_{2}$ foi bem similar em ambos os isômeros.

Os cálculos ofereceram os espectros teóricos de IV dos isômeros 1 e 2 do complexo [ $\mathrm{Zn}$ (INHHQ) $\mathrm{Cl}_{2}$ ] (Figuras $4 \mathrm{~S}$ e $5 \mathrm{~S}$, respectivamente), que foram usados para comparação com o espectro experimental obtido por Freitas (Figura 6S). ${ }^{1}$ Visualmente, o espectro experimental é mais similar ao espectro teórico do isômero 2 , devido a um conjunto de bandas presente na região $3000-4000 \mathrm{~cm}^{-1}$ que são observados em ambos os espectros, enquanto que uma banda bem pronunciada na região $3000-3500 \mathrm{~cm}^{-1}$, presente no espectro do isômero 1 , não é encontrada no espectro experimental. As principais frequências são apresentadas na Tabela 6.

Tabela 6. Principais vibrações do ligante INHHQ $\left(\mathrm{cm}^{-1}\right)$. Os valores se encontram fora de escala

\begin{tabular}{lccc}
\hline & $\begin{array}{c}\text { Isômero 1 } \\
\text { (Teórico) }\end{array}$ & $\begin{array}{c}\text { Isômero 2 } \\
\text { (Teórico) }\end{array}$ & Experimental ${ }^{1}$ \\
\hline Estiramento $\mathrm{O}_{1}-\mathrm{H}$ & 3274 & 3742 & 3477 \\
Estiramento $\mathrm{N}_{1}-\mathrm{H}$ & 3592 & 3460 & 3222 \\
Estiramento $\mathrm{C}_{1}=\mathrm{O}_{2}$ & $1649-1652$ & $1628-1639$ & 1699 \\
Estiramento $\mathrm{C}_{2}=\mathrm{N}_{2}$ & 1684 & $1628-1639$ & 1622 \\
Estiramento $\mathrm{C}_{3}=\mathrm{N}_{3}$ & 1578 & 1512 & 1554 \\
Estiramento $\mathrm{C}_{8}-\mathrm{OH}$ & 1339 & 1296 & - \\
\hline
\end{tabular}

O espectro teórico do isômero 1 obtido possui a banda referente ao estiramento $\mathrm{N}_{1}-\mathrm{H}$ como última banda de expressão, seguida pela banda referente ao estiramento $\mathrm{O}_{1}-\mathrm{H}$, o que vai contra o proposto no espectro experimental de Freitas, em que a última banda do espectro é atribuída ao estiramento $\mathrm{O}_{1}-\mathrm{H}$, seguida pela banda do estiramento $\mathrm{N}_{1}-\mathrm{H} \cdot{ }^{1}$ No caso do espectro do isômero 2, a ordem das bandas é a mesma sugerida por Freitas, também é a mesma ordem observada nos espectros teórico e experimental ${ }^{1}$ do ligante INHHQ, fato que pode ser constatado observando estes dois estiramentos diretamente na ferramenta GaussView (ver link disponível na Figura 7Sa, no material suplementar). Era esperado encontrar esses estiramentos em valores diferentes no complexo devido a coordenação, mas não era esperada uma inversão, indicando que o espectro obtido por Freitas é mais coerente com o isômero 2.
Os valores de números de onda obtidos para os estiramentos $\mathrm{C}_{1}=\mathrm{O}_{2}, \mathrm{C}_{2}=\mathrm{N}_{2}$ e $\mathrm{C}_{3}=\mathrm{N}_{3}$ no isômero 1 e $\mathrm{C}_{8}=\mathrm{O}_{1}, \mathrm{C}_{2}=\mathrm{N}_{2}$ e $\mathrm{C}_{3}=\mathrm{N}_{3}$ no isômero 2 deveriam ser menores do que os mesmos valores obtidos para o ligante, uma vez que, após a coordenação, a densidade dessas ligações deveria se deslocar para o centro metálico, tornando a ligação mais fraca. Tal tendência pode ser observada em alguns trabalhos envolvendo a complexação do $\mathrm{O}$ carbonílico em ligantes do tipo $\mathrm{N}$-acil-hidrazona. ${ }^{42,43}$ Comparando-se os valores de frequência obtidos para os dois isômeros com os obtidos para o ligante, observa-se a diminuição da frequência do estiramento $\mathrm{C}_{1}=\mathrm{O}_{2}$ nos complexos (de 1667 no ligante livre para um valor dentro da faixa 1649-1652 no isômero 1, e um valor na faixa 1628-1639 no isômero 2). Observandose esse estiramento diretamente no programa Gaussian 09 (ver link disponível na Figura 7Sb, no material suplementar), no isômero 1, a frequência vibraçional desse estiramento é bem maior do que no isômero 2, quando se esperaria o contrário (uma baixa frequência vibracional no isômero 1 graças à coordenação de $\mathrm{O}_{2}$ ), indicando que a coordenação de $\mathrm{O}_{2}$ não é favorável. Comparando-se as frequências observadas para esse estiramento no ligante e no isômero 1 diretamente pelo Gaussian 09, é possível concluir que a frequência não diminuiu após a coordenação. No estiramento $\mathrm{C}_{3}=\mathrm{N}_{3}$, os números de onda diminuíram de 1594 no ligante para 1578 (isômero 1) e, no isômero 1 , a frequência vibracional desse estiramento é bem maior do que no isômero 2, quando se tem 1512 (isômero 2), de modo que a frequência vibracional correspondente foi observada de forma mais forte no isômero 1, bem similar a observada no ligante (ver link disponível na Figura 7S, no material suplementar), indicando que a ligação $\mathrm{C}_{3}=\mathrm{N}_{3}$ se encontra mais forte nesse isômero e essa coordenação é pouco efetiva. Já para o estiramento $\mathrm{C}_{2}=\mathrm{N}_{2}$, os números de onda aumentaram de 1619 no ligante para um valor dentro da faixa 1628-1639 em ambos os isômeros, um valor que, em teoria, não era esperado. Tal como o observado para as ligações $\mathrm{C}_{1}=\mathrm{O}_{2}$ e $\mathrm{C}_{3}=\mathrm{N}_{3}$, a vibração $\mathrm{C}_{2}=\mathrm{N}_{2}$ possui maior frequência vibracional no isômero 1 , indicando que a coordenação de $\mathrm{N}_{2}$ nesse isômero é menos efetiva do que no isômero 2.

Pelos dados de IV encontrados nesse trabalho, o espectro experimental do complexo [ $\left.\mathrm{Zn}(\mathrm{INHHQ}) \mathrm{Cl}_{2}\right]$ obtido por Freitas apresenta maior coerência com o complexo do isômero 2 do que o do isômero 1. Esses e os demais dados corroboram que a estrutura mais provável para os complexos [ $\left.\mathrm{Zn}(\mathrm{INHHQ}) \mathrm{Cl}_{2}\right],\left[\mathrm{Zn}\left(8-\mathrm{H}_{2} \mathrm{QH}\right) \mathrm{Cl}_{2}\right]$ e $[\mathrm{Zn}(8-$ $\left.\mathrm{H}_{2} \mathrm{QS}\right) \mathrm{Cl}_{2}$ ] é a estrutura referente ao isômero 2 proposto neste trabalho (mostrado anteriormente na Figura 4).

\section{CONCLUSÃO}

Foi realizado o estudo teórico, por meio de cálculos de DFT, dos ligantes INHHQ, 8- $\mathrm{H}_{2} \mathrm{QH}$ e 8- $\mathrm{H}_{2} \mathrm{QS}$, três promissores potenciais fármacos para o combate da DA, e de quatro isômeros para cada um dos complexos [ $\mathrm{Zn}(\mathrm{INHHQ}) \mathrm{Cl}_{2}$ ], $\left[\mathrm{Zn}\left(8-\mathrm{H}_{2} \mathrm{QH}\right) \mathrm{Cl}_{2}\right]$ e $\left[\mathrm{Zn}\left(8-\mathrm{H}_{2} \mathrm{QS}\right) \mathrm{Cl}_{2}\right]$. Os resultados obtidos para os ligantes indicaram que os parâmetros geométricos se encontraram de acordo com os observados experimentalmente para o INHHQ e o $8-\mathrm{H}_{2} \mathrm{QH}$, e a análise dos percentuais de participação no HOMO dos três ligantes mostrou que a coordenação desses se dará, preferencialmente, de forma tridentada, pelos átomos $\mathrm{O}_{1}, \mathrm{~N}_{2}$ e $\mathrm{N}_{3}$, indicando que esse mesmo perfil de coordenação deve ser encontrado em outros ligantes derivados da 8-HQ com substituintes do tipo $N$-acil-hidrazona.

Analisando-se os resultados obtidos para os complexos, verificou-se que os isômeros 2, 3 e 4 de cada correspondem à mesma estrutura. Os valores de distância de ligação revelaram que o átomo de $\mathrm{O}$ dos ligantes que formará a coordenação mais efetiva com o íon $\mathrm{Zn}^{2+}$ é $\mathrm{O}_{1}$, indicando que o isômero 2 é o mais coerente para os complexos propostos. A análise das energias das estruturas também 
corrobora essa conclusão, já que os isômero 2 dos três complexos possuem energias inferiores a dos seus respectivos isômeros 1. Além disso, a análise dos dados espectroscópicos indicou que o espectro de IV experimental obtido por Freitas é mais coerente com o espectro teórico do isômero 2, em que as frequências vibracionais referentes aos estiramentos $\mathrm{C}_{1}=\mathrm{O}_{2}, \mathrm{C}_{2}=\mathrm{N}_{2}$ e $_{3}=\mathrm{N}_{3}$ são maiores no isômero 1 , indicando que as coordenações de $\mathrm{O}_{2}, \mathrm{~N}_{2}$ e $\mathrm{N}_{3}$ são pouco efetivas nesse isômero. Assim, concluímos que, do ponto de vista teórico, a estrutura mais razoável obtida pela coordenação de ligantes derivados da 8-HQ com substituintes do tipo $N$-acil-hidrazonas ao íon zinco(II), com dois átomos de cloro adicionais, é a estrutura referente ao isômero 2 proposto neste trabalho, cujo esquema reacional pode ser visto na figura que abre este artigo. Espera-se, com os dados aqui obtidos, ajudar a compreender a forma de coordenação dessa classe de ligantes ao íon zinco, auxiliando assim nos estudos que visam compreender os mecanismos de ação desses potenciais fármacos como agente no combate da DA.

\section{MATERIAL SUPLEMENTAR}

Algumas imagens e tabelas dos sistemas utilizados neste trabalho estão disponíveis em http://quimicanova.sbq.org.br, na forma de arquivo PDF, com acesso livre.

\section{AGRADECIMENTOS}

Os autores agradecem ao CNPq (Conselho Nacional Científico e Tecnológico, Brasil), à FAPERJ (Fundação Carlos Chagas Filho de Amparo à Pesquisa do Estado do Rio de Janeiro) e à CAPES (Coordenação de Aperfeiçoamento de Pessoal de Nível Superior) pelas bolsas concedidas.

\section{REFERÊNCIAS}

1. Freitas, L. V.; Tese de Doutorado, Pontíficia Universidade Católica do Rio de Janeiro, Brasil, 2014.

2. http://www.who.int/medicines/areas/priority_medicines/ BP6_11Alzheimer.pdf, acessada em agosto 2018.

3. De Falco, A.; Cukierman, D. S.; Hauser-Davis, R. A.; Rey, N. A.; Quím. Nova 2016, 39, 63.

4. Ruggiero, R. N.; Bueno-Júnior, L. S.; Ross, J. B.; Fachim, H. A.; Padovan-Neto, F. E.; Merlo, S.; Rohner, C. J. S.; Ikeda, E. T.; Brusco, J.; Moreira, J. E.; Medicina (Ribeirão Preto) 2011, 44, 143.

5. Atrían-Blasco, E., Conte-Daban, A.; Hureau, C.; Dalton Trans. 2017, 46, 12750.

6. Hardy, J.; Higgins, G.; Science 1992, 256, 184.

7. Hardy, J., Selkoe, D. J.; Science 2002, 297, 353.

8. https://www.ninds.nih.gov/Disorders/All-Disorders/Alzheimers-DiseaseInformation-Page, acessada em agosto 2018.

9. Lambert, M. P.; Barlow, A. K.; Chromy, B. A.; Edwards, C.; Freed, R.; Liosatos, M.; Morgan, T. E.; Rozovsky, I.; Trommer, B.; Viola, K. L.; Lee, J. Y.; Cole, T. B.; Palmiter, R. D.; Suh, S. W.; Koh, J. Y.; Proc. Natl. Acad. Sci. U. S. A. 2002, 99, 7705.

10. Brito-Moreira, J.; Lourenco, M. V.; Oliveira, M. M.; Ribeiro, F. C.; Ledo, J. H.; Diniz, L. P.; Vital, J. F. S.; Magdesian, M. H.; Melo, H. M.; Barros- Aragão, F.; Souza, J. M.; Alves-Leon, S. V.; Gomes, F. C. A.; Clarke, J. R.; Figueiredo, C. P.; De Felice, F. G.; Ferreira, S. T.; J. Biol. Chem. 2017, 292, 7327.

11. Levine III, H.; Ding, Q.; Walker, J. A.; Voss, R. S.; Augelli-Szafran, C. E.; Neurosci. Lett. 2009, 465, 99.

12. Diniz, L. P.; Tortelli, V.; Matias, I. C. P.; Morgado, J.; Araújo, A. P. B.; Melo, H. M.; Silva, G. S. S.; Alves-Leon, S. V.; Marcondes, J.; Ferreira, S. T.; De Felice, F. G.; Gomes, F. C. A.; J. Neurosci. 2017, 1, 1.
13. Findeis, M. A.; Pharmacol. Ther. 2007, 116, 266.

14. Zirah, S.; Kozin, S. A.; Mazur, A. K.; Blond, A.; Cheminant, M.; Segalas-Milazzo, L.; Debey, P.; Rebuffat, S.; J. Biol. Chem. 2006, 281, 2151.

15. Tsvetkov, P. O.; Kulikova, A. A.; Golovin, A. V.; Tkachev, Y. V.; Archakov, A. I.; Kozin, S. A.; Makarov, A. A.; Biophys. J. 2010, 99, 84.

16. Roberts, B. R.; Ryan, T. M.; Bush, A. I.; Masters, C. L.; Duce, J. A.; J. Neurochem. 2012, 120, 149 .

17. Huang, W.; Wei, W.; Shen, Z.; RSC Adv. 2014, 4, 52088.

18. Mamelak, M.; Neurobiol. Aging 2007, 28, 1340.

19. Haeffner, F.; Barnham, K.; Bush, A.; Brinck, T.; J. Mol. Model. 2010, 16,1103 .

20. Henriques, G. S.; Hirata, M. H.; Cozzolino, S. M. F.; Rev. Nutr. 2003 , $16,333$.

21. Melov, S.; Trends Neurosci. 2002, 25, 121.

22. Marino, T.; Russo, N.; Toscano, M.; Pavelka, M.; Interdiscip. Sci.: Comput. Life Sci. 2010, 2, 57.

23. Alies, B.; Conte-Daban, A.; Sayen, S.; Collin, F.; Kieffer, I.; Guillon, E.; Faller, P.; Hureau, C.; Inorg. Chem. 2016, 55, 10499.

24. Istrate, A. N.; Kozin, S. A.; Zhokhov, S. S.; Mantsyzov, A. B.; Kechko, O. I.; Pastore, A.; Makarov, A. A.; Polshakov, V. I.; Sci. Rep. 2016, 6, 1.

25. Adlard, P. A.; Parncutt, J. M.; Finkelstein, D. I.; Bush, A. I.; J. Neurosci. 2010, 30,1631.

26. Colvin, R. A.; Fontaine, C. P.; Laskowski, M.; Thomas, D.; Eur. J. Pharmacol. 2003, 479, 171.

27. Corcoran, N. M.; Martin, D.; Hutter-Paier, B.; Windisch, M.; Nguyen, T.; Nheu, L.; Sundstrom, L. E.; Costello, A. J.; Hovens, C. M.; J. Clin. Neurosci. 2010, 17, 1025.

28. Freitas, L. V.; Silva, C. C. P.; Ellena, J.; Costa, L. A. S.; Rey, N. A.; Spectrochim. Acta, Part A 2013, 116, 41.

29. Deraeve, C.; Boldron, C.; Maraval, A.; Mazarguil, H.; Gornitzka, H.; Vendier, L.; Pitie, M.; Meunier, B.; Chem. - Eur. J. 2008, 14, 682.

30. Olivieri, V.; Vecchio, G.; Eur. J. Med. Chem. 2016, 120, 252.

31. Prachayasittikul, V.; Prachayasittikul, S.; Ruchirawat, S.; Prachayasittikul, V.; Drug Des., Dev. Ther. 2013, 7, 1157.

32. Marino, T.; Russo, N.; Toscano, M.; Pavelka, M.; J. Quantum Chem. 2012, 112, 2109.

33. Rodríguez-Santiago, L.; Alí-Torres, J.; Vidossich, P.; Sodupe, M.; Phys. Chem. Chem. Phys. 2015, 17, 13582

34. Kupershmidt, L.; Amit, T.; Bar-Am, O.; Weinreb, O.; Youdim, M. B.; Mol. Neurobiol. 2012, 46, 217.

35. Faux, N, G.; Ritchie, C. W.; Gunn, A.; Rembach, A.; Tsatsanis, A.; Bedo, J.; Harrison, J.; Lannfelt, L.; Blennow, K.; Zetterberg, H.; Ingelsson, M.; Masters, C. L.; Tanzi, R. E.; Cummings, J. L.; Rebanho, C. M.; Bush, A. I.; J. Alzheimer's Dis. 2010, 20, 509.

36. Gomes, L. M.; Vieira, R. P.; Jones, M. R.; Wang, M. C.; Dyrager, C.; Souza-Fagundes, E. M.; Da Silva, J. G.; Storr, T.; Beraldo, H.; J. Inorg. Biochem. 2014, 139, 106.

37. Wang, Z.; Wang, Y.; Li, W.; Mao, F.; Sun, Y.; Huang, L.; Li, X.; ACS Chem. Neurosci. 2014, 5, 952.

38. Hauser-Davis, R. A.; Freitas, L. V.; Cukierman, D. S.; Cruza, W. S.; Miotto, M. C.; Landeira-Fernandez, J.; Valiente-Gabioud, A. A.; Fernández, C. O.; Rey, N. A.; Metallomics 2015, 7, 743.

39. Frisch, M. J.; Trucks, G. W.; Schlegel, H. B.; Scuseria, G. E.; Robb, M. A.; Cheeseman, J. R.; Scalmani, G.; Barone, V.; Petersson, G. A.; Nakatsuji, H.; Li, X.; Caricato, M.; Marenich, A.; Bloino, J.; Janesko, B. G.; Gomperts, R.; Mennucci, B.; Hratchian, H. P.; Ortiz, J. V.; Izmaylov, A. F.; Sonnenberg, J. L.; Williams-Young, D.; Ding, F.; Lipparini, F.; Egidi, F.; Goings, J.; Peng, B.; Petrone, A.; Henderson, T.; Ranasinghe, D.; Zakrzewski, V. G.; Gao, J.; Rega, N.; Zheng, G.; Liang, W.; Hada, M.; Ehara, M.; Toyota, K.; Fukuda, R.; Hasegawa, J.; Ishida, M.; Nakajima, T.; Honda, Y.; Kitao, O.; Nakai, H.; Vreven, T.; Throssell, K.; 
Montgomery, J. A.; Jr.; Peralta, J. E.; Ogliaro, F.; Bearpark, M.; Heyd, J. J.; Brothers, E.; Kudin, K. N.; Staroverov, V. N.; Keith, T.; Kobayashi, R.; Normand, J.; Raghavachari, K.; Rendell, A.; Burant, J. C.; Iyengar, S. S.; Tomasi, J.; Cossi, M.; Millam, J. M.; Klene, M.; Adamo, C.; Cammi, R.; Ochterski, J. W.; Martin, R. L.; Morokuma, K.; Farkas, O.; Foresman, J. B.; Fox, D. J.; Gaussian 09, Revision-B.01-SMP; Gaussian, Inc., Wallingford CT, 2009.
40. Torres, V. V.; Rayol, V. A.; Magalhães, M.; Viana, G. M.; Aguiar, L. C. S.; Machado, S. P.; Orofino, H.; D’elia, E.; Corros. Sci. 2014, 79, 108. 41. Silva, E. T., Casellato, A.; Machado, S. P.; Quim. Nova 2016, 39, 437.

42. Despaigne, A. A. R., Silva, J. G.; Carmo, A. C. M.; Piro, O. E.; Castellano, E. E.; Beraldo, H.; Inorg. Chim. Acta 2009, 362, 2117.

43. Despaigne, A. A. R.; Silva, J. G.; Carmo, A. C. M.; Sives, F.; Piro, O. E.; Castellano, E. E.; Beraldo, H.; Polyhedron 2009, 28, 3797. 